\title{
Regulation of Escherichia coli adenylate cyclase activity during hexose phosphate transport
}

\author{
Valérie Dumay, $†$ Antoine Danchin and Martine Crasnier $\ddagger$
}

Author for correspondence: Martine Crasnier. Tel: +1 619534 2608. Fax: +1 6195347108.
e-mail: mcrasnier@ucsd.edu

Unité de Régulation de I'Expression Génétique (Centre National de la Recherche Scientifique Unité Associée 1129), Institut Pasteur, 28 rue du Docteur Roux, 75724 Paris cedex 15, France

\begin{abstract}
In Escherichia coli, CAMP levels vary with the carbon source used in the culture medium. These levels are dependent on the cellular concentration of phosphorylated EnzymellAalc, a component of the glucose-phosphotransferase system, which activates adenylate cyclase (AC). When cells are grown on glucose 6-phosphate (Glc6P), the CAMP level is particularly low. In this study, we investigated the mechanism leading to the low CAMP level when GIc6P is used as the carbon source, i.e. the mechanism preventing the activation of AC

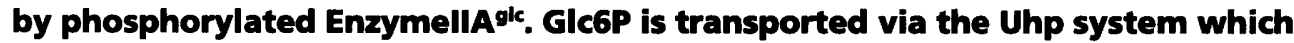
is inducible by extracellular GIc6P. The Uhp system comprises a permease UhpT and three proteins UhpA, UhpB and UhpC which are necessary for uhpT gene transcription. Controlled expression of UhpT in the absence of the regulatory proteins (UhpA, UhpB and UhpC) allowed us to demonstrate that (i) the Uhp regulatory proteins do not prevent the activation of $A C$ by direct interaction with EnzymellA gle and (ii) an increase in the amount of UhpT synthesized (corresponding to an increase in the amount of Glc6P transported) correlates with a decrease in the CAMP level. We present data indicating that Glc6P per se or its degradation is unlikely to be responsible for the low CAMP level. It is concluded that the level of CAMP in the cell is determined by the flux of GIc6P through UhpT.
\end{abstract}

Keywords: Escherichia coli, adenylate cyclase, cyclic AMP, phosphotransferase system, glucose 6-phosphate transport

\section{INTRODUCTION}

In Escherichia coli, intracellular cAMP concentration is dependent on the carbon source used in the culture medium (Epstein et al., 1975; Joseph et al., 1982). The lowest concentration is obtained when cells are grown on glucose or glucose 6-phosphate (Glc6P). A model has been proposed which explains the low level of cAMP observed when cells grow with glucose as the carbon source. This model involves the phosphotransferase system (PTS) which regulates adenylate cyclase (AC) (Saier \& Feucht, 1975; Postma et al., 1993). EnzymeIIA ${ }^{\text {gle }}$, a glucose-specific component of the PTS is phosphorylated via a phosphorylation cascade including

†Present address: RITE, 9-2 Kizugawadai, Kizu-cho, Soraku-gun, Kyoto 619-02, Japan.

¥Present address: University of California San Diego, Department of Biology, La Jolla, CA 92093-0116, USA.

Abbreviations: $A C$, adenylate cyclase; Fru6P/Fru1P, fructose 6phosphate/1-phosphate; GIC6P/GIc1P, glucose 6-phosphate/1-phosphate; Man6P, mannose 6-phosphate; PTS, phosphotransferase system.
EnzymeI and HPr, the general components of the PTS. When phosphorylated, EnzymeIIA ${ }^{\text {glc }}$ activates AC. During glucose transport, the intracellular concentration of phosphorylated EnzymeIIA ${ }^{\text {glc }}$ decreases causing a decrease in intracellular cAMP concentration (Feucht \& Saier, 1980; Postma et al., 1981). This model is supported by the fact that total cAMP in $\Delta c r r$ strains (lacking EnzymeIIA $^{\text {gle }}$ ) is low and close to that of a wild-type strain grown on glucose. However, the mechanism leading to the activation of AC by EnzymeIIA ${ }^{\text {glc }}$ remains to be explained.

Glc6P is transported into the cell via the Uhp system which is inducible by extracellular Glc6P (Dietz \& Heppel, 1971a). The Uhp system consists of a permease UhpT (encoded by $u h p T$ ) which is transcriptionally regulated by three regulatory proteins, UhpA, UhpB and UhpC (encoded by $u b p A, u b p B$ and $u b p C$, respectively) (Weston \& Kadner, 1987). In the presence of external Glc6P, the membrane proteins UhpB and UhpC probably phosphorylate UhpA, promoting the transcription of the $u b p T$ gene. UhpA and UhpB belong to the family of two 
Table 1. E. coli strains and plasmids used in this study

\begin{tabular}{|c|c|c|}
\hline $\begin{array}{l}\text { Strain or } \\
\text { plasmid }\end{array}$ & Genotype or description & Origin \\
\hline TP2503 & $\mathrm{F}^{-} x y l-5 \operatorname{argH} 1$ ilv $A$ & De Reuse \& Danchin (1988) \\
\hline TP2504 & $\mathrm{F}^{-} x y l-5$ argH1 ilv $A$ ptsG22 zcf-229:: $\operatorname{Tn} 10$ & De Reuse \& Danchin (1988) \\
\hline TP2100 & $\mathrm{F}^{-} x y l-5$ argH1 ilv $A \Delta \operatorname{lac} X 74$ & Roy et al. (1983) \\
\hline TP2862 & $\mathrm{F}^{-} x y l-5$ argH1 aroB ilv $A \Delta c r r:$ :kan & Lévy et al. (1990) \\
\hline AE304-3 & $\mathrm{F}^{-}$tna:: Tn10 $\Delta l a c X 74$ thi tsx T6 bglR 11 bglB3 $(A m)$ & A. Wright \\
\hline TP9522 & RK4981 tna:: $\operatorname{Tn} 10$ & P1/AE304-3 × RK4981 \\
\hline TP9523 & TP2503 tna:: $\operatorname{Tn} 10 \Delta u b p T 2050$ & P1/TP9522 × TP2503 \\
\hline TP9525 & ТP9524 $\Delta(u b p A B C T)$ & $\operatorname{Tn} 10$ excision of TP9524 \\
\hline TP9526 & TP9525 tna:: $\operatorname{Tn} 10$ & P1/AE304-3 × TP9525 \\
\hline TP9527 & TP2100 tna:: $\operatorname{Tn} 10 \Delta(u b p A B C T)$ & P1/TP9526 $\times$ TP2100 \\
\hline AT2243-11 & $\mathrm{Hfr} u b p-1$ ton $A 22$ ompF627 relA1 spoT1 metB1 pyrE42 T2 & Ferenci et al. (1971) \\
\hline TP9528 & AT2243-11 $\operatorname{tna}:: \operatorname{Tn} 10$ & P1/AE304-3 $\times$ AT2243-11 \\
\hline TP9529 & TP2503 tna:: $\operatorname{Tn} 10 u b p-1$ & P1/TP9528 $\times$ TP2503 \\
\hline TP9530 & ТP9529 ubp-1 & $\operatorname{Tn} 10$ excision of TP9529 \\
\hline DF40 & $\begin{array}{l}\text { Hfr pgi-2 ompF627 relA1 spoT1 pit-10 morB1 phoM510 fadL701 } \\
\text { fbuA22 garB10 }\end{array}$ & Fraenkel \& Levisohn (1967) \\
\hline TST6 & $\begin{array}{l}\mathrm{F}^{-} \text {malF3089:: } \operatorname{Tn} 10[\text { araD139] ptsF25 deoC1 } \Delta(\operatorname{argF}-\text { lac }) 169 \\
\text { rpsl150 relA1 flbB5301 }\end{array}$ & T. Silhavy (Princeton, NJ) \\
\hline TP9531 & DF40 malF3089:: $\operatorname{Tn} 10$ & P1/TST6 $\times$ DF40 \\
\hline TP9532 & TP9530 malF3089:: Tn10 pgi-2 & P1/TP9531 × TP9530 \\
\hline FB8 & $\mathrm{F}^{-}$prototrophic & Bruni et al. (1977) \\
\hline FB8 $\Delta p t s$ & FB8 $\Delta(p t s H$ ptsI crr $):$ :kan & Biville et al. (1991) \\
\hline TP9503 & TP2503 $\Delta c r r:$ : kan & P1/TP2862 $\times$ TP2503 \\
\hline TP9533 & TP9503 tna::Tn10ubp-1 & P1/TP9528 $\times$ TP9503 \\
\hline DF1671 DZ1 & $\mathrm{F}^{-}$thr-1 leuB6 bisG1 str-115 pgi-2 rpsL $\Delta\left(e d d-q^{w} f\right) 15$ & $\begin{array}{l}\text { Fraenkel \& Banerjee (1972) } \\
\text { via B. Bachmann }\end{array}$ \\
\hline CAG12074 & Wild-type zea-3068: : $\operatorname{Tn} 10$ & Singer et al. (1989) \\
\hline TP9534 & DF1671 DZ1 zea-3068:: Tn10 & P1/CAG12074 × DF1671 DZ1 \\
\hline TP9535 & TP2503 zea-3068:: Tn10 $\Delta(e d a-q w f) 15$ & P1/TP9534 × TP2503 \\
\hline \multicolumn{3}{|l|}{ Plasmids } \\
\hline pJF118HE & ColE1 lac $I^{\mathrm{q}} \operatorname{tac} P \operatorname{rrnB~A\mathrm {p}^{\mathrm {r}}}$ & Fürste et al. (1986) \\
\hline pDIA187 & Derivative of $\mathrm{pBR} 322$ containing the $u b p T$ gene, $\mathrm{Ap}^{\mathrm{r}}$ & This work \\
\hline pDIA188 & Derivative of $\mathrm{pJF} 118 \mathrm{HE}$ containing the $u b p T$ gene, $A \mathrm{p}^{\mathrm{r}}$ & This work \\
\hline pDIA4705 & Derivative of $\mathrm{pBR} 322$ containing the $\mathrm{cr}$ gene, $A \mathrm{p}^{r}$ & Zeng et al. (1992) \\
\hline
\end{tabular}

component regulatory systems (Weston \& Kadner, 1988) and UhpC shows sequence similarity with UhpT (Island $e t$ al., 1992). It has been suggested that UhpB and UhpC interact during induction (Island \& Kadner, 1993).

Glc6P does not inhibit AC activity when measured in toluenized cells (Harwood \& Peterkofsky, 1975) or with purified AC (Yang \& Epstein, 1983). The mechanism leading to a low level of cAMP when Glc6P is used as the carbon source is not yet understood. Expression of glucose-PTS proteins is not diminished in strains grown on Glc6P as shown by fusion experiments (De Reuse \& Danchin, 1988), which indicates that the low cAMP level is not related to a low level of expression of EnzymeIIA ${ }^{\text {glc }}$. In this study, we analyse the effect of various hexose phosphates on cAMP production. This level is shown to be dependent on the presence of phosphorylated EnzymeIIA $^{\text {glc }}$. We then investigate the activity of phosphorylated EnzymeIIA ${ }^{\text {glc }}$ during growth on Glc6P. We show that activation of $A C$ by phosphorylated EnzymeIIA ${ }^{\text {glc }}$ is prevented when Glc6P is transported into the cell.

\section{METHODS}

Bacterial strains and plasmids. The strains and plasmids used in this work are listed in Table 1. The growth medium was either LB or M63 minimal medium (Miller, 1992) supplemented with the required amino acids $(1 \mathrm{mM})$, thiamine $\left(5 \mu \mathrm{g} \mathrm{ml}^{-1}\right)$ and a carbon source $(0.4 \%)$. When required, ampicillin and tetra- 
cycline were added at $100 \mu \mathrm{g} \mathrm{ml}^{-1}$ and $10 \mu \mathrm{g} \mathrm{m}^{-1}$, respectively. P1 transductions were done as described by Miller (1992). Uhpconstitutive strains were isolated on M63 plates supplemented with fructose 1-phosphate (Fru1P) (Ferenci et al., 1971). Strains lacking phosphoglucoisomerase $\left(p g i^{-}\right)$produced pink colonies on glucose MacConkey plates and showed slow growth on glucose M63 plates. Strain TP9535 lacking Glc6P dehydrogenase $\left(q w f^{-}\right)$was checked for the lack of Glc6P dehydrogenase activity according to the method of Fraenkel \& Levisohn (1967). Strain TP9525 which contains a deletion of the ubp genes ( $\triangle u b p A B C T$ ) was obtained as follows. The $\operatorname{Tn} 10$ transposon of strain TP9524 (which contains a deletion in the $u b p T$ gene, Table 1) was removed from the chromosome according to the method of Bochner et al. (1980) as modified by Maloy \& Nunn (1981). Tet $^{\mathrm{s}}$ clones were analysed by PCR for the presence of the $u b p C$ gene. One of the clones showing a deletion of the $u b p C$ gene was further analysed by Southern blot hybridization (Southern, 1975).

Determination of total CAMP concentrations. In E. coli, more than $99 \%$ of the cAMP synthesized is excreted in the culture medium (Matin \& Matin, 1982). In addition, under our experimental conditions, the excretion rate of cAMP is a linear function of the intracellular concentration (Epstein et al., 1975; Crasnier et al., 1994). For these reasons, total cAMP was measured. A radioimmunological assay was performed as described by Guidi-Rontani et al. (1981) with exponential phase cells grown in M63. The amount of cAMP was expressed as pmol (mg dry wt bacteria) $)^{-1}$. Total cAMP (mg dry wt bacteria) $)^{-1}$ was constant during the exponential phase of growth. Values were calculated as the means of three determinations.

Measurements of CAMP synthesis. In vivo measurements of cAMP synthesis were performed as described by Harman \& Botsford (1979). Bacteria were grown in M63 to midexponential phase. Cells were centrifuged and resuspended in fresh M63 medium supplemented with $0.1 \%$ casamino-acids and chloramphenicol at $100 \mu \mathrm{g} \mathrm{ml}^{-1}$. The cell suspension was aerated at $37^{\circ} \mathrm{C}$, samples were taken at zero time and after 5,10 , 20 and $30 \mathrm{~min}$. Total cAMP was determined as described above and rates of cAMP synthesis were calculated from the slopes of plots.

Cloning of the uhpt gene. A promoterless uhpT gene was obtained by PCR using chromosomal DNA from strain TP2503. The primers were chosen according to the sequence of the $u b p T$ gene (Island et al., 1992). The upstream primer (CCATCGAT'T'TACAATGCATGCCTCACGC) was located 41 nucleotides upstream of the ribosome-binding site. The downstream primer (CGGAATTCGTTTATGCCACTGTCAACTG) covered the translation termination codon of $u h p T$. The amplified $1.5 \mathrm{~kb}$ fragment was digested with $\mathrm{ClaI}$ and EcoRI (whose restriction sites were introduced in the primers) and cloned into pBR322 to give pDIA187. This plasmid placed the $u b p T$ gene under the control of the anti-tet promoter. Ap ${ }^{r}$ transformants of strain TP9523 $(\Delta u h p T)$ were obtained on LB plates but failed to grow with Glc6P or fructose 6-phosphate (Fru6P) in agreement with the fact that overproduction of the $u b p T$ gene has been shown to be deleterious to the cells (Kadner et al., 1992). Therefore, the $u h p T$ gene was further subcloned as an EcoRI-HindIII fragment of pDIA187 into pJF118HE. The plasmid thus obtained, pDIA188, carries the $u b p T$ gene under the control of the tac promoter (Fig. 1).

Measurements of transport and inducer exclusion by the PTS. Uptake of $\alpha-\left[\right.$ methyl $\left./{ }^{14} \mathrm{C}\right]$ glucoside or $\left[{ }^{14} \mathrm{C}\right]$ mannose by intact cells was measured according to the method of Bouvet \& Grimont (1987). Cultures were grown in MM63 supplemented

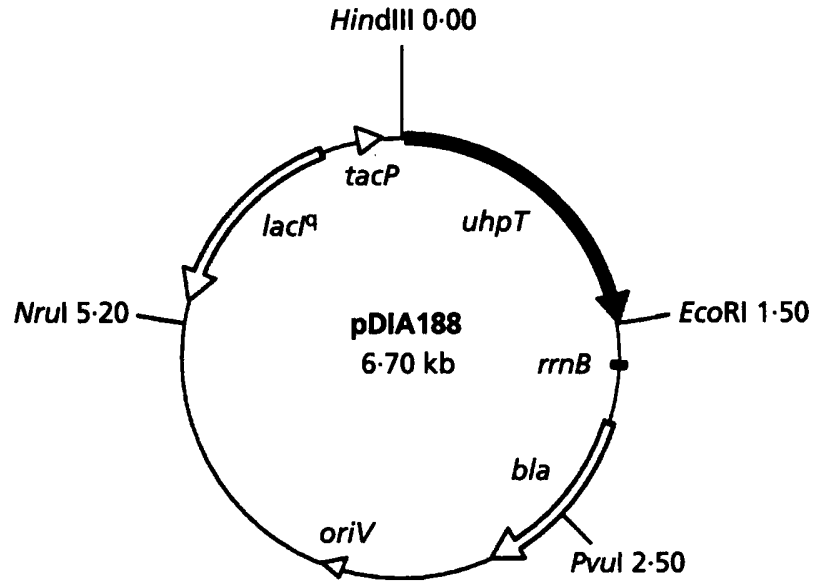

Fig. 1. Plasmid pDIA188. Plasmid pDIA188 carries the uhpT gene under the control of the tac promoter.

with $0.4 \%$ pyruvate plus $1 \mathrm{mM}$ glucose or $1 \mathrm{mM}$ mannose. Exponential phase cells were washed twice in M63 containing chloramphenicol at $40 \mu \mathrm{g} \mathrm{ml}^{-1}$. The samples were shaken for $15 \mathrm{~min}$ at $25^{\circ} \mathrm{C}$ before starting the experiment at zero time by adding pyruvate $(10 \mathrm{mM}$ final concentration) and $\alpha-[$ metbyl${ }^{14} \mathrm{C}$ glucoside $\left(50 \mu \mathrm{M}, 14.8 \times 10^{7} \mathrm{~Bq} \mathrm{mmol}^{-1}\right)$ or $\left[{ }^{14} \mathrm{C}\right]$ mannose $\left(100 \mu \mathrm{M}, 14.8 \times 10^{7} \mathrm{~Bq} \mathrm{mmol}^{-1}\right)$. When needed, hexose phosphates at $1 \mathrm{mM}$ final concentration were added at zero time.

Inducer exclusion can be analysed on M63 plates supplemented with $1 \%(\mathrm{w} / \mathrm{v})$ glucose, $0.2 \%$ lactose and $40 \mu \mathrm{g} \mathrm{X}-\mathrm{Gal} \mathrm{m} \mathrm{l}^{-1}$ (Tyler et al., 1969). Under these conditions, dephosphorylated EnzymeIIA ${ }^{\text {glc }}$ prevents lactose entrance by interacting with the lactose permease. Consequently, wild-type strains grow as white colonies. Replacement of glucose by Glc6P in these plates made it possible to analyse the ability of this carbon source to cause inducer exclusion.

\section{RESULTS}

\section{Effect of hexose phosphates on CAMP levels}

Glc6P is transported into the cell by the UhpT permease which also mediates the entry of a large variety of hexose phosphates (Winkler, 1966). We investigated cAMP production by the wild-type strain TP2503 growing with different hexose phosphates. With Glc6P, total cAMP was threefold lower than that obtained with pyruvate and twofold lower than that obtained with glucose (Table 2), in agreement with previous data (Epstein et al., 1975). Growth on Fru6P or mannose 6-phosphate (Man6P) resulted in an increased level of cAMP as compared to that obtained with Glc6P, although strain TP2503 grew on Fru6P, Man6P or Glc6P with the same doubling time. However Fru6P and Man6P, which are transported into the cell by UhpT, have been shown to be poor inducers of the Uhp system. This prompted us to analyse the effect of the hexose phosphates on cAMP production in a Uhpconstitutive derivative of strain TP2503. The $u b p^{c} \mathrm{mu}-$ 
Table 2. cAMP levels in strains grown on different hexose phosphates

Values are means of three determinations \pm SEM. ND, not determined; NG, no growth.

\begin{tabular}{|lccc|}
\hline Carbon source & \multicolumn{3}{c|}{ Total cAMP [pmol (mg dry wt) ${ }^{-1}$ ] } \\
\cline { 2 - 4 } & TP2503 (wild-type) & TP9529 (uhp $\boldsymbol{p}^{\mathbf{c}}$ ) & TP9503 (Acr) $)^{\mathbf{T}}$ \\
& & & \\
\hline Glucose & $300 \pm 100$ & $250 \pm 50$ & $230 \pm 30$ \\
Glc6P & $150 \pm 20$ & $150 \pm 20$ & $80 \pm 20$ \\
Fru6P & $800 \pm 150$ & $150 \pm 10$ & $100 \pm 10$ \\
Man6P & $1000 \pm 200$ & $220 \pm 20$ & $100 \pm 10$ \\
Glc1P & $3200 \pm 1000$ & $320 \pm 30$ & ND \\
Fru1P & NG & $500 \pm 50$ & NG \\
Pyruvate & $1000 \pm 200$ & $1100 \pm 200$ & $150 \pm 50$ \\
\hline
\end{tabular}

tation (ubp-1) from strain AT2243-11 ${ }^{\mathrm{c}}$ (Table 1) was transduced into strain TP2503 to give strain TP9529. Whatever the hexose phosphate used for growth (Fru6P or Man6P), TP9529 showed a low level of cAMP very similar to that obtained with strain TP2503 grown on Glc6P (Table 2). The $u b p^{c}$ mutation did not affect cAMP production of strain TP9529 grown either on glucose or pyruvate. Therefore, different substrates of the UhpT permease were able to decrease the cAMP level provided that UhpT was expressed. In agreement with this observation, growth of the wild-type strain TP2503 with Fru6P in the presence of $0.01 \%$ Glc6P as an inducer (Shattuck-Eidens \& Kadner, 1981) resulted in a fourfold decrease in the cAMP level as compared to that obtained in the absence of induction [200 versus $800 \mathrm{pmol}$ (mg dry $w t)^{-1}$ ].

Glucose 1-phosphate (Glc1P) is a non-inducing UhpT substrate whose glucose moiety can enter the cell via the PTS after periplasmic dephosphorylation (Pradel \& Boquet, 1989; Dietz \& Heppel, 1971b). With wild-type strain TP2503, growth on Glc1P gave a cAMP level 10fold higher than on glucose (Table 2), analogous to the high level of cAMP in cells grown in a limiting concentration of glucose (Dumay \& Crasnier, 1994). However, with the $u b p^{c}$ strain, Glc1P growth resulted in a low level of cAMP (Table 2).

Another non-inducing substrate for Uhp' is Fru1P (Pogell et al., 1966; Ferenci et al., 1971). When the ubp $p^{\mathrm{c}}$ strain TP9529 was grown on Fru1P, the cAMP level was slightly increased as compared to that of the same strain grown on the other hexose phosphates (Table 2, see Discussion).

Taken together, these results indicated that a decrease in the cAMP level might correlate with an increase in transport via UhpT, whatever the hexose phosphate transported. Table 2 also shows that the cAMP level of a $\Delta c r r$ strain (TP9503) grown on Glc6P, Fru6P or Man6P was decreased as compared to that of the wild-type strain grown on the same carbon source. This result indicates that high cAMP levels require the presence of EnzymeIIA ${ }^{\text {glc }}$.

\section{Effect of Glc6P metabolism on CAMP levels}

A zwf strain lacking Glc6P dehydrogenase (TP9535, Table 1) showed a low level of cAMP when grown on Glc6P [220 pmol (mg dry wt $\left.)^{-1}\right]$. As a $p g i^{-}$strain lacking phosphoglucose isomerase (TP9532, Table 1) which, as previously reported (Fraenkel \& Levisohn, 1967), has increased doubling time when grown on Glc6P as compared to wild-type strains, also has a relatively low cAMP level [ $400 \mathrm{pmol}(\mathrm{mg} \text { dry } \mathrm{wt})^{-1}$ ]. These relatively low cAMP levels in cells grown on Glc6P might be related to the concentration of Glc6P in the cell. Therefore, we measured the cAMP in a $p g i$ strain grown on Fru6P. In this strain the reversible transformation of Fru6P into Glc6P does not occur. Strains TP9529 (ubp $\left.p g i^{+}\right)$and TP9532 ( $\left.u b p^{\mathrm{c}} p g i^{-}\right)$grown on Fru6P showed the same growth rate and had similar low quantities of cAMP, i.e. $200 \mathrm{pmol}\left(\mathrm{mg}\right.$ dry wt) ${ }^{-1}$ with TP9532 versus $150 \mathrm{pmol}$ (mg dry wt) ${ }^{-1}$ with TP9529. These results suggest that Glc6P per se is not causing a decrease in the cAMP level. Addition of $0.1 \%$ deoxyglucose 6-phosphate (a nonmetabolizable analogue of Glc6P) to cells of strain TP9529 $\left(u h p^{c}\right)$ growing on pyruvate decreased the cAMP level from 1000 to $300 \mathrm{pmol}$ ( $\mathrm{mg}$ dry wt $)^{-1}$. In these conditions, the addition of deoxyglucose 6-phosphate did not affect growth of strain TP9529.

\section{Controlled expression of UhpT}

To further analyse the role of UhpT in the regulation of the cAMP level, a plasmid was constructed containing the hexose phosphate permease gene $(u h p T)$ under the control of the tac promoter (pDIA188, Fig. 1). Due to the presence of the $l a c I^{\mathrm{q}}$ repressor gene on the plasmid, the expression of $u b p T$ was dependent on the amount of IPTG in the culture medium. A strain containing a deletion of the entire ubp operon was constructed as described in Methods (TP9525, Table 1). This deletion was introduced into strain TP2100 (a $\Delta$ lac derivative of TP2503). The resulting strain TP9527 ( $\Delta u b p A B C T \Delta l a c)$ transformed with pDIA188 (Fig. 1) was grown in Glc6P M63 with different concentrations of IPTG. The cAMP levels and the doubling times of growth as a function of 


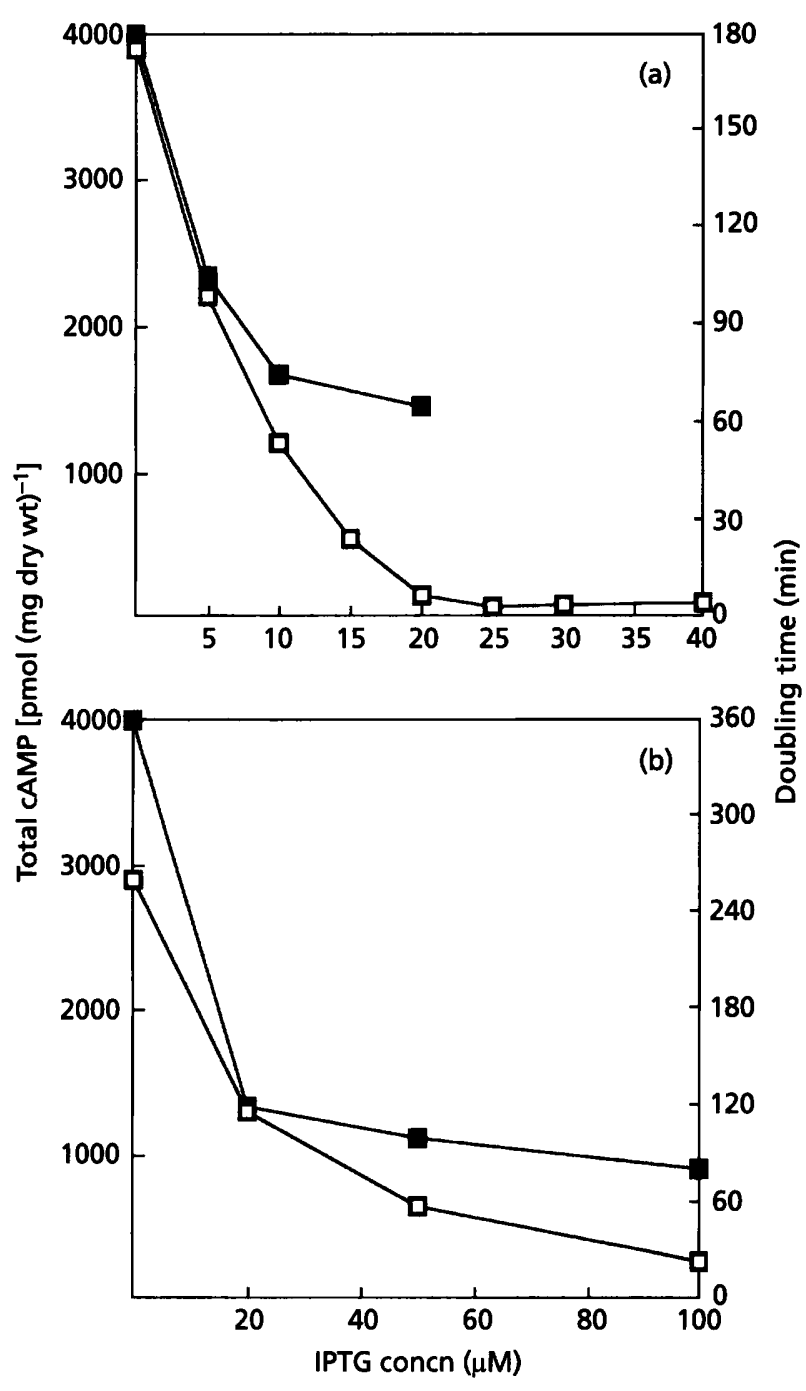

Fig. 2. Variation of CAMP levels and growth rate with IPTG concentration. Strain TP9527 ( $\triangle$ uhpABCT) containing pDIA188 was grown in minimal medium M63 supplemented with $0.4 \%$ GIc6P (a) or $0.4 \%$ Fru1P (b). The total CAMP ( $\square$ ) and the doubling time ( $\square$ ) were measured as a function of the IPTG concentration in the growth medium.

the IPTG concentration are shown in Fig. 2. In the absence of IPTG, strain TP9527(pDIA188) grew with a doubling time of $3 \mathrm{~h}$ and produced an elevated amount of cAMP [about 3000 to 4000 pmol (mg dry wt $)^{-1}$, Fig. 2a]. Increasing the IPTG concentration from 0 to $20 \mu \mathrm{M}$ resulted in a decrease of the doubling time which correlated with a decrease of the cAMP level (Fig. 2a). The doubling time and the cAMP level of the wild-type strain were obtained when an IPTG concentration of $20 \mu \mathrm{M}$ IPTG was used. Above $20 \mu \mathrm{M}$ IPTG, the growth stopped after two doubling times (see Discussion). With glucose instead of Glc6P, there was no variation in the doubling time or the cAMP levels as a function of the IPTG concentration, even above $20 \mu \mathrm{M}$ IPTG.

With TP9527(pDIA488) grown on Fru1P, $100 \mu$ M IPTG was required to obtain a growth rate and a cAMP level

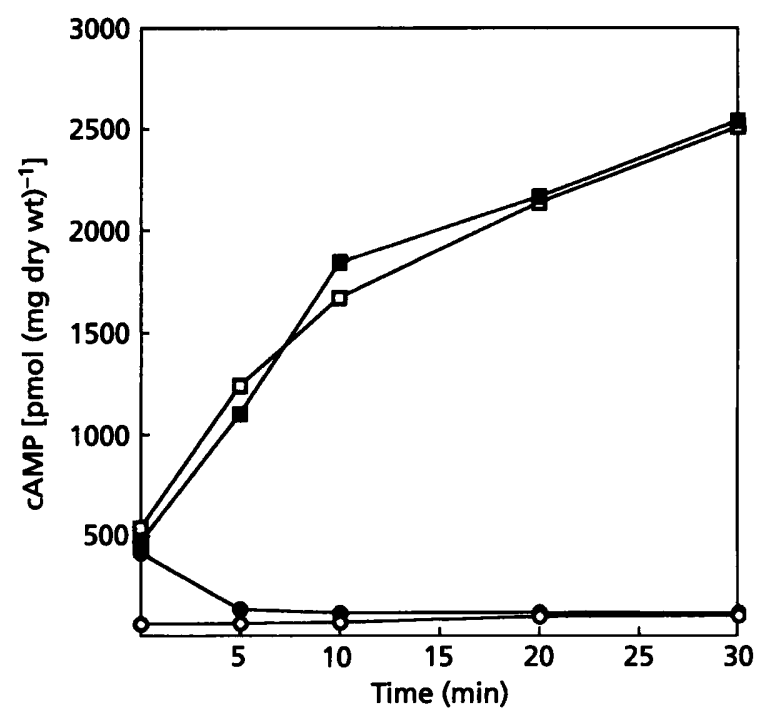

Fig. 3. CAMP synthesis in different strains after growth on Glc6P or GIc. CAMP synthesis was measured as described in Methods with strain TP2503 (wild-type) grown on Glc6P ( $\square$ ) or glucose ( $\square$ ). CAMP synthesis was not observed with strain TP9503 ( $\Delta$ crr) grown on Glc6P (O). AC from strain TP2503 grown on Glc6P was inhibited when Glc6P or Glc was present in the assay medium (O).

comparable to those of the $u b p^{\mathrm{c}}$ strain TP9529 grown on Glc6P (Fig. 2b).

\section{Activity of EnzymellA ${ }^{\text {glc }}$ during hexose phosphate transport}

AC activity measured in resting cell suspensions incubated with casamino-acids (Methods) was not detectable in a $\Delta c r r$ strain (TP9503) grown on Glu6P while, in a wildtype strain (TP2503) grown on Glc6P or glucose, activity was $130 \mathrm{pmol} \mathrm{cAMP} \min ^{-1}\left(\mathrm{mg}\right.$ dry wt) ${ }^{-1}$ (Fig. 3). These data, and the fact that $\beta$-galactosidase activities with a cya-lac $Z$ protein fusion [encoded by pDIA483 (Crasnier $e t$ al., 1994)] were similar in strains grown on glucose or Glc6P (data not shown), suggest that the amounts of $A C$ and phosphorylated EnzymeIIA ${ }^{\text {glc }}$ available for AC activation are the same in resting cell suspensions obtained from cells grown either on glucose or on Glc6P. Addition of Glc (which is known to cause EnzymeIIA ${ }^{\text {glc }}$ dephosphorylation) or Glc6P in the assay medium resulted in inhibition of activity (Fig. 3).

The ability of Glc6P to cause inducer exclusion through dephosphorylation of EnzymeIIA ${ }^{\text {glc }}$ was analysed on M63 plates supplemented with Glc6P (see Methods). In contrast to that which was observed with glucose, both wild-type strain FB8 and FB8Dpts exhibited a blue phenotype on these plates, i.e. no inducer exclusion as in the wild-type strain, Glc6P does not act on AC via dephosphorylation of EnzymeIIA ${ }^{\text {glc }}$. As a control, inducer exclusion was observed (white phenotype) with strain FB8Dpts transformed with plasmid pDIA4705 which carries the $c r r$ gene. 


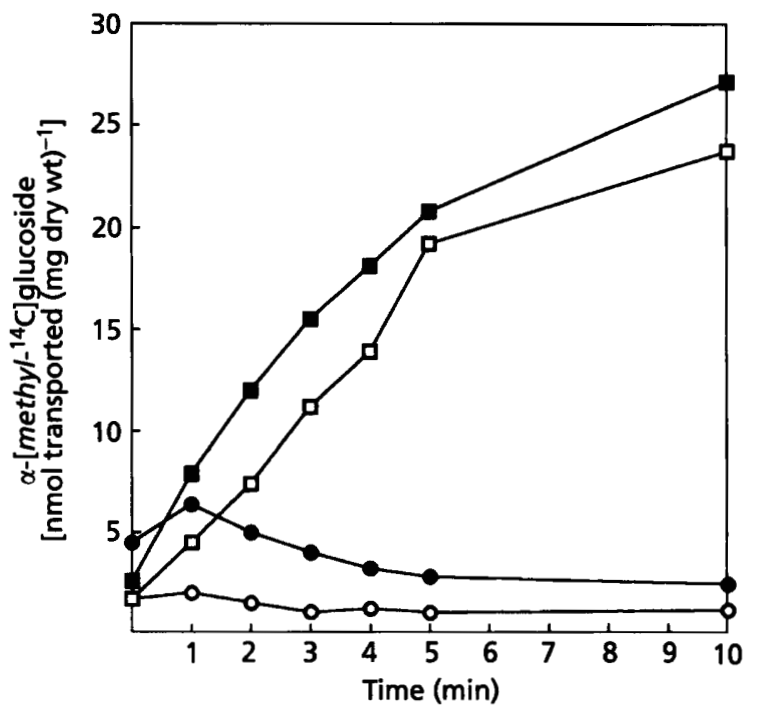

Fig. 4. Inhibition of $\alpha-\left[\right.$ methy $\left./{ }^{-14} \mathrm{C}\right]$ glucoside transport by Fru6P in strains TP9529 (uhpc $\mathrm{pgi}^{+}$) and TP9532 (uhpc pgi ${ }^{-}$). Uptake of $\alpha$-[methyl $\left.-{ }^{14} \mathrm{C}\right]$ glucoside by strain TP9529 (口) and strain TP9532 () was measured as described in Methods. Zero time corresponds to the addition of $\alpha-\left[\right.$ methyl $\left.-{ }^{14} \mathrm{C}\right]$ glucoside to the reaction mixture. In the presence of $1 \mathrm{mM}$ Fru6P, $\alpha$-[methyl${ }^{14} \mathrm{C}$ glucoside uptake was inhibited in both strain TP9529 (O) and strain TP9532 (O).

\section{Effect of hexose phosphates on PTS-sugar transport}

Glc6P has been shown to inhibit PTS-mediated transport (Kornberg, 1973; Lengeler \& Steinberger, 1978). We analysed the effect of Glc6P on the uptake of $\alpha$-[methyl${ }^{14} \mathrm{C}$ glucoside, a non-metabolizable analogue of glucose. As reported by Lengeler \& Steinberger (1978), an inhibitory effect of Glc6P on the uptake of $\alpha$-[metbyl$\left.{ }^{14} \mathrm{C}\right]$ glucoside was observed only when the Uhp system was induced. The $u b p^{\mathrm{c}}$ strain TP9529 exhibited the same inhibition of $\alpha$-methylglucoside uptake in the presence of Glc6P. Addition of Fru6P, Man6P or deoxyglucose 6phosphate also resulted in an inhibition of $\alpha$-[metbyl${ }^{14}$ C]glucoside transport in strain TP9529 (data not shown), indicating that Glc6P was not the only sugar phosphate that could cause the decreased $\alpha$-[metbyl${ }^{14} \mathrm{C}$ gglucoside transport rate. The same experiments were carried out with strain TP9532, a $p g i^{-}$derivative of strain TP9529 (in this strain, Glc6P cannot be synthesized from Fru6P). The inhibitory effect of Fru6P on $\alpha$ methylglucoside transport is shown in Fig. 4. The same inhibition was observed with both $p g i^{+}$and $p g i{ }^{-}$strains, suggesting that Glc6P per se was not responsible for the decreased $\alpha-\left[\right.$ metby $\left.l{ }^{14} \mathrm{C}\right]$ glucoside transport rate.

We then investigated the effect of Glc6P transport on $\left[{ }^{14} \mathrm{C}\right]$ mannose uptake in a $\Delta c r$ strain (lacking EnzymeIIA $\left.^{\text {glc }}\right)$. A total deletion of the $\mathrm{cr}$ gene was transduced into the $u b p^{\mathrm{c}}$ strain TP9529. The resulting strain TP9533 was able to transport mannose through its specific PTS. As shown in Fig. 5, mannose uptake was also inhibited by the addition of $1 \mathrm{mM}$ Glc6P. This result indicated that Glc6P transport inhibited the PTS-de-

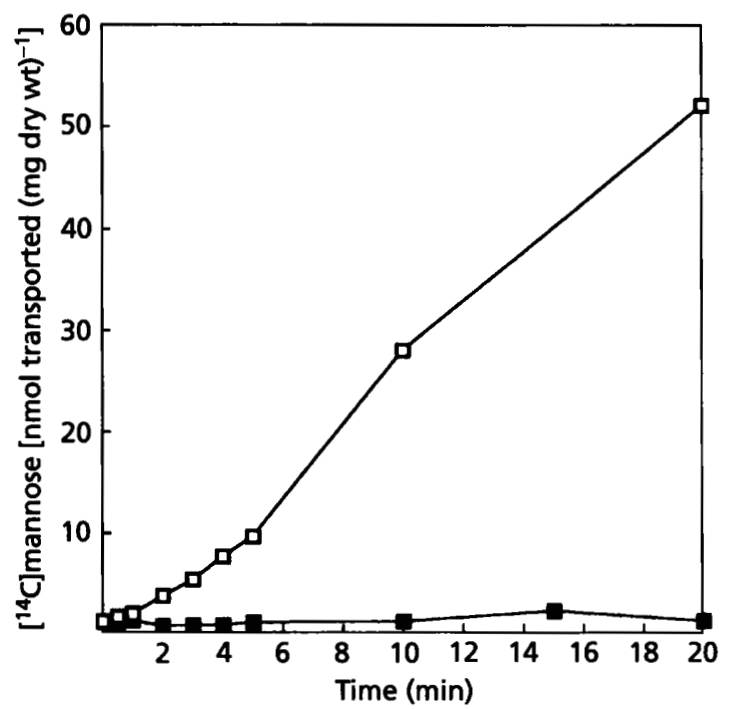

Fig. 5. Inhibition of $\left[{ }^{14} \mathrm{C}\right]$ mannose transport by Glc6P in strain TP9533 (uhpc $\Delta$ crr). Uptake of $\left[{ }^{14} \mathrm{C}\right]$ mannose by strain TP9533 $(\square)$ was measured as described in Methods. Addition of $1 \mathrm{mM}$ Glc6P resulted in an inhition of the uptake $(\boldsymbol{D})$.

pendent transport of mannose in the absence of EnzymeII ${ }^{\text {gle }}$.

\section{DISCUSSION}

Strains growing in the presence of Glc6P as sole carbon source show low levels of cAMP but the regulatory mechanism leading to the low level of cAMP is not known. We have shown here that Glc6P degradation is not directly involved in the regulation of the cAMP level. Transport of a non-metabolizable analogue of Glc6P (deoxyglucose 6-phosphate) decreased the cAMP level when added to cells growing on pyruvate cells. Strains lacking either Glc6P dehydrogenase ( $2 w f$ ) or phosphoglucose isomerase $(p g i)$ had a low level of cAMP when grown on Glc6P, close to that of a wild-type strain grown on Glc6P. In addition, Glc6P per se was not involved in the regulation of the cAMP level as a $p g i$ strain showed low cAMP levels when grown in the presence of Fru6P. The fact that the cAMP level in a pgi strain grown on Glc6P was increased as compared to the same strain grown on Fru6P [ 400 versus 200 pmol ( $\left.\mathrm{mg}^{\mathrm{dry}} \mathrm{wt}\right)^{-1}$ ] was most likely due to the slow growth observed with Glc6P as compared to Fru6P.

We also showed that a low level of cAMP was obtained only when UhpT, the Glc6P permease, is induced and Glc6P (or a UhpT substrate) transported as shown by the following results: (1) in the absence of Glc6P transport, a Uhp-constitutive strain grown on pyruvate showed a high level of cAMP (Table 2); (2) different substrates of the UhpT permease were able to decrease the cAMP level provided that the UhpT permease was expressed; and (3) increasing the amount of UhpT synthesized, by using a vector carrying the $u b p T$ gene under the tac promoter (IPTG-inducible), led to a decrease in the cAMP level 
when the hexose phosphates transported by UhpT were added. In the absence of IPTG, slow growth was observed and an elevated amount of cAMP was measured as compared to a wild-type strain grown on Glc6P. In agreement with this data, Yang et al. (1979) reported that Glc6P-limited growth in a chemostat also resulted in a high cAMP level. With Glc6P, both growth rate and cAMP levels characteristic of a wild-type strain were obtained for $20 \mu \mathrm{M}$ IPTG. Fürste et al. (1986) also showed that, with a similar expression vector, induction by IPTG is detectable in the range $10-100 \mu \mathrm{M}$. Above $20 \mu \mathrm{M}$ IPTG, the growth stopped, as demonstrated previously by Kadner et al. (1992), showing that amplified UhpT transport inhibits growth. With Fru1P, the same response to IPTG was observed with a shift in the curve as compared to that obtained with Glc6P (five times more IPTG required to obtain both the same growth rate and cAMP level). In addition, the cAMP level of the $u b p^{c}$ strain grown on Fru1P was slightly increased as compared to that of the same strain grown on the other hexose phosphates (Table 2). These data could be related to the low affinity of Fru1P for UhpT as compared to that of Glc6P (Pogell et al., 1966; Maloney et al., 1990). Taken together, these results suggest that UhpA, UhpB and UhpC did not play any role in decreasing the cAMP level in cells growing in the presence of hexose phosphates, although, in wild-type cells, these proteins may have an indirect effect on the cAMP level by regulating the synthesis of UhpT. Thus the level of cAMP is dependent on the amount of Glc6P (or any other hexose phosphates) transported by the UhpT permease.

We propose that the regulation of the cAMP level when Glc6P was used as carbon source occurred during Glc6P transport. The UhpT transport system has been proposed to function in two modes (Maloney et al., 1990). In one mode, two Glc $6 \mathrm{P}^{-}$anions move into the cell in exchange for the export of one Glc6 $\mathrm{P}^{2-}$. This exchange is equivalent to the net entry of one Glc6 $\mathrm{P}^{2-}$ and two $\mathrm{H}^{+}$and is thermodynamically equivalent to a $2 \mathrm{H}^{+}$: $\mathrm{Glc} 6 \mathrm{P}^{2-}$ symport with $\Delta \mathrm{pH}$ acting as the sole driving force. It has been reported that a collapse of the proton electrochemical gradient leads to a decrease of AC activity (Peterkofsky \& Gazdar, 1979). However, under our experimental conditions, a collapse of the gradient by transport via UhpT is unlikely to occur as proton pumping under aerobic steady-state conditions is too rapid for a collapse of the gradient to take place. The exchange system by UhpT can also operate by moving two $\mathrm{H}_{2} \mathrm{PO}_{4}^{-}$anions out and one Glc6 $\mathrm{P}^{2-}$ in. Although it has been shown that phosphate is necessary for the activation of the AC-PTS complex (Peterkofsky, 1988), it is unlikely that Glc6P transport leads to a depletion of the phosphate pool which is tightly maintained in E. coli. However, the possibility remains that local phosphate concentrations at the membrane level are decreased during Glu6P transport, affecting the activation of AC by EnzymeIIA ${ }^{\text {glc }}$.

Both functions of the PTS, i.e. glucose transport and activation of $\mathrm{AC}$, are inhibited during Glc6P transport. To explain the inhibitory effect of Glc6P on PTS transport, it has been proposed that the PTS permeases,
EnzymeIICBA $^{\mathrm{mtl}}$ or EnzymeIICB ${ }^{\text {gut }}$, were inhibited by intracellular hexose phosphates (Lengeler \& Steinberger, 1978). However, attempts to reproduce the inhibitory effect of Glc6P on the PTS permeases in vitro have failed (Jacobson et al., 1983). In strain TP2504 (lacking EnzymeIICB ${ }^{\text {glc }}$ ) grown on Glc6P, a low cAMP level was measured $\left[200 \mathrm{pmol}(\mathrm{mg} \text { dry } \mathrm{wt})^{-1}\right]$, indicating that transport of Glc6P remained effective in maintaining a low cAMP level in the absence of the glucose permease. Therefore an inhibition of EnzymeIICB ${ }^{\text {glc }}$ by hexose phosphate (which could have affected EnzymeIIA ${ }^{\text {gle }}$ regulation of $\mathrm{AC}$ ) could not be related to the low cAMP level. Finally, the fact that EnzymeIIA ${ }^{\text {gle }}$ was present in strains grown on Glc6P (as shown by measurement of $A C$ activity) and was probably phosphorylated (as shown by the inducer exclusion experiment) suggested that $A C$ cannot be activated by phosphorylated EnzymeII ${ }^{\text {glc }}$ during Glc6P transport. Thus it is worth noting that the mechanism of 'catabolite repression' by hexose phosphate may be different from the one occurring with glucose. It must be emphasized that regulation of AC activity during Glc6P transport probably occurs at the membrane level. This is supported by data indicating that the soluble enzymes of the PTS exist as peripheral membrane constituents associated with the integral membrane Enzyme II complex (Saier et al., 1982) or with data showing a localization of Enzyme I to the inner surface of the cytoplasmic membrane (Ghosh et al., 1989).

\section{ACKNOWLEDGEMENTS}

We are very grateful to Milton $H$. Saier, Jr and Bernard Lubochinsky for critical reading of the manuscript. We thank Gaetano Villani for stimulating discussions. We also thank Véronique Cadet for technical assistance and Odile Bouvet for her valuable help during the uptake experiments. We are grateful to Agnès Ullmann for providing us with cAMP antibodies.

\section{REFERENCES}

Biville, F., Turlin, E. \& Gasser, F. (1991). Mutants of Escherichia coli producing pyrroloquinoline quinone. $J$ Gen Microbiol 137, 1775-1782.

Bochner, B. R., Huang, H. C., Schieven, G. L. \& Ames, B. N. (1980). Positive selection for loss of tetracycline resistance. J Bacteriol 143, 926-933.

Bouvet, O. M. M. \&Grimont, P. A. D. (1987). Diversity of the phosphoenol pyruvate/glucose phosphotransferase system in the Enterobacteriaceae. Ann Inst Pasteur Microbiol 138, 3-13.

Bruni, C. B., Colantuoni, V., Sbordone, L., Cortese, R. \& Blasi, F. (1977). Biochemical and regulatory properties of E. coli $\mathrm{K} 12$ bis $T$ mutants. $J$ Bacteriol 130, 4-10.

Crasnier, M., Dumay, V. \& Danchin, A. (1994). The catalytic domain of Escherichia coli adenylate cyclase as revealed by deletion analysis of the cya gene. Mol \& Gen Genet 243, 409-416.

De Reuse, H. \& Danchin, A. (1988). The ptsH, ptsI and $c r r$ genes of the Escherichia coli phosphoenolpyruvate-dependent phosphotransferase system: a complex operon with several modes of transcription. J Bacteriol 170, 3827-3837.

Dietz, G. W. \& Heppel, L. A. (1971a). Studies on the uptake of hexose phosphates. II: The induction of the glucose 6-phosphate 
transport system by exogeneous but not endogenously formed glucose 6-phosphate. J Biol Chem 246, 2885-2890.

Dietz, G. W. \& Heppel, L. A. (1971b). Studies on the uptake of hexose phosphates. III: Mechanism of uptake of glucose 1phosphate in Eschericbia coli. J Biol Chem 246, 2891-2897.

Dumay, V. \& Crasnier, M. (1994). Role of the phosphotransferase system in Eschericbia coli strains deficient in hexose phosphate transport. FEMS Microbiol Lett 116, 209-214.

Epstein, W., Rothman-Denes, L. B. \& Hesse, J. (1975). Adenosine $3^{\prime}: 5^{\prime}$-cyclic monophosphate as mediator of catabolite repression in Escherichia coli. Proc Natl Acad Sci US A 72, 2300-2304.

Ferenci, T., Kornberg, H. L. \& Smith, J. (1971). Isolation and properties of a regulatory mutant in the hexose phosphate transport system of Escherichia coli. FEBS Lett 13, 133-136.

Feucht, B. U. \& Saier, M. H. (1980). Fine control of adenylate cyclase by the phosphoenolpyruvate:sugar phosphotransferase systems in Eschericbia coli and Salmonella typhimurium.J Bacteriol 141, 603-610.

Fraenkel, D. G. \& Banerjee, S. (1972). Detection mapping of $₹ w f$, the gene for a constitutive enzyme, glucose 6-phosphate dehydrogenase in Escherichia coli.Genetics 71, 481-489.

Fraenkel, D. G. \& Levisohn, S. R. (1967). Glucose and gluconate metabolism in an Escherichia coli mutant lacking phosphoglucose isomerase. $J$ Bacteriol 93, 1571-1578.

Fürste, J. P., Pansegrau, W., Frank, R., Blocker, H., Scholz, P., Bagdasarian, M. \& Lanka, E. (1986). Molecular cloning of the plasmid RP4 primase region in a multi-host-range tac $P$ expression vector. Gene 48, 119-131.

Ghosh, B. K., Owens, K., Pietri, R. \& Peterkofsky, A. (1989). Localization to the inner surface of the cytoplasmic membrane by immunoelectron microscopy of enzyme I of the phosphoenolpyruvate:sugar phosphotransferase system of Escherichia coli. Proc Natl Acad Sci US A 86, 849-853.

Guidi-Rontani, C., Danchin, A. \& Ullmann, A. (1981). Isolation and characterization of an Escberichia coli mutant affected in the regulation of adenylate cyclase. $J$ Bacteriol 148, 753-761.

Harman, J. G. \& Botsford, J. L. (1979). Synthesis of adenosine $3^{\prime}: 5^{\prime}$ cyclic monophosphate in Salmonella typhimurium growing in continuous culture. J Gen Microbiol 110, 243-246.

Harwood J. P. \& Peterkofsky, A. (1975). Glucose-sensitive adenylate cyclase in toluene-treated cells of Escherichia coli B. J Biol Chem 250, 4656-4662.

Island, M. D. \& Kadner, R. J. (1993). Interplay between the membrane-associated $\mathrm{UhpB}$ and $\mathrm{UhpC}$ regulatory proteins. $J$ Bacteriol 175, 5028-5034.

Island M. D., Wei, B. Y. \& Kadner, R. J. (1992). Structure and function of the $u h p$ genes for the sugar phosphate transport system in Escherichia coli and Salmonella typhimurium. J Bacteriol 174, 2754-2762.

Jacobson, G. R., Lee, C. A., Leonard, J. E. \& Saier, M. H., Jr (1983). Mannitol-specific Enzyme II of the bacterial phosphotransferase system. J Biol Chem 258, 10748-10756.

Joseph, E., Bernsley, C., Guiso, N. \& Ullmann, A. (1982). Multiple regulation of the activity of adenylate cyclase in Escherichia coli. Mol $\mathcal{E}$ Gen Genet 185, 262-268.

Kadner, R. J., Murphy, P. \& Stephens, C. M. (1992). Two mechanisms for growth inhibition by elevated transport of sugar phosphates in Escherichia coli. J Gen Microbiol 138, 2007-2014.

Kornberg, H. L. (1973). Fine control of sugar uptake by Escherichia coli. Symp Soc Exp Biol 27, 175-193.

Lengeler, J. \& Steinberger, H. (1978). Analysis of regulatory mechanisms controlling the activity of the hexitol transport systems in Escherichia coli K12. Mol \& Gen Genet 167, 75-82.

Lévy, S., Zeng, G. Q. \& Danchin, A. (1990). Cyclic AMP synthesis in Escherichia coli strains bearing known deletions in the pts phosphotransferase operon. Gene 86, 27-33.

Maloney, P. C., Ambudkar, S. V., Anantharam, V., Sonna, L. A. \& Varadhachary, A. (1990). Anion-exchange mechanisms in bacteria. Microbiol Rev 54, 1-17.

Maloy, S. R. \& Nunn, W. D. (1981). Selection for loss of tetracycline resistance by Escherichia coli. J Bacteriol 145, 1110-1112.

Matin, A. \& Matin, M. K. (1982). Cellular levels, excretion, and synthesis rates of cyclic AMP in Escherichia coli grown in continuous culture. J Bacteriol 149, 801-807.

Miller, J. F. (1992). A Short Course in Bacterial Genetics: a Laboratory Manual and Handbook for Eschericbia coli and Related Bacteria, 2nd edn. Cold Spring Harbor, NY: Cold Spring Harbor Laboratory.

Peterkofsky, A. (1988). Redistribution of phosphate pools and the regulation of Escherichia coli adenylate cyclase activity. Arch Biochem Biophys 265, 227-233.

Peterkofsky, A. \& Gazdar, C. (1979). Escherichia coli adenylate cyclase complex : regulation by the proton electrochemical gradient. Proc Natl Acad Sci US A 76, 1099-1103.

Pogell, B. M., Maity, B. R., Frumkin, S. \& Shapiro, S. (1966). Induction of an active transport system for glucose 6-phosphate in Escherichia coli. Arch Biochem Biophys 116, 406-415.

Postma, P. W., Schuitema, A. \& Kwa, C. (1981). Regulation of methyl- $\beta$-galactoside permease activity in pts and $\mathrm{crr}$ mutants of Salmonella typhimurium. Mol \& Gen Genet 181, 448-453.

Postma, P. W., Lengeler, J. W. \& Jacobson, G. R. (1993). Phosphoenolpyruvate: carbohydrate phosphotransferase systems of bacteria. Microbiol Rev 57, 543-594.

Pradel, E. \& Boquet, P. L. (1989). Mapping of the Escherichia coli acid glucose-1-phosphatase gene $a g p$ and analysis of its expression in vivo by use of an agp $p$ - pho $A$ protein fusion. J Bacteriol 171, 3511-3517.

Roy, A., Danchin, A., Joseph, E. \& Ullmann, A. (1983). Two functional domains in adenylate cyclase of Escherichia coli.J Mol Biol 165, 197-202.

Saier, M. H., Jr \& Feucht, B. U. (1975). Coordinate regulation of adenylate cyclase and carbohydrate permeases by the phosphoenolpyruvate:sugar phosphotransferase system in Salmonella typhimurium. J Biol Chem 250, 7078-7080.

Saier, M. H., Jr, Cox, D. F., Feucht, B. U. \& Novotny, M. J. (1982). Evidence for the functional association of Enzyme I and Hpr of the phosphoenolpyruvate-sugar phosphotransferase system with the membrane in sealed vesicles of Escherichia coli. J Cell Biochem 18, 231-238.

Shattuck-Eidens, D. M. \& Kadner, R. J. (1981). Exogenous induction of the Escherichia coli hexose phosphate transport system defined by $u h p$-lac operon fusions. J Bacteriol 148, 203-209.

Shattuck-Eidens, D. M. \& Kadner, R. J. (1983). Molecular cloning of the $u b p$ region and evidence for a positive activator for expression of the hexose phosphate transport system of Escherichia coli. $J$ Bacteriol 155, 1062-1070.

Singer, M., Baker, T. A., Schnitzler, G., Deischel, S. M., Goel, M., Dove, W., Jaacks, K. J., Grossman, A. D., Erickson, J. W. \& Gross, C. A. (1989). A collection of stains containing genetically linked alternating antibiotic resistance elements for genetic mapping of Escherichia coli. Microbiol Rev 53, 1-24.

Southern, E. (1975). Detection of specific sequences among DNA fragments separated by gel electrophoresis. J Mol Biol 98, 503-517.

Tyler, B., Wishnow, R., Loomis, W. F. \& Magasanik, B. (1969). 
Catabolite repression gene of Escherichia coli. $J$ Bacteriol 100, 809-816.

Weston, L. A. \& Kadner, R. J. (1987). Identification of Uhp polypeptides and evidence for their role in exogenous induction of the sugar phosphate transport system of Escherichia coli K12. $J$ Bacteriol 169, 3546-3555.

Weston, L. A. \& Kadner, R. J. (1988). Role of uhp genes in expression of the Escherichia coli sugar-phosphate transport system. $J$ Bacteriol 170, 3375-3383.

Winkler, H. H. (1966). A hexose-phosphate transport system in Escherichia coli. Biochim Biopbys Acta 117, 231-240.

Yang, J. K. \& Epstein, W. (1983). Purification and characterization of adenylate cyclase from Escherichia coli K12. J Biol Chem 258, 3750-3758.

Yang, J. K., Bloom, R. W. \& Epstein, W. (1979). Catabolite and transient repression in Escherichia coli do not require Enzyme I of the phosphotransferase system. J Bacteriol 138, 275-279.

Zeng, G. Q., De Reuse, H. \& Danchin, A. (1992). Mutational analysis of the EnzymeIII ${ }^{\mathrm{Glc}}$ of the phosphoenolpyruvate phosphotransferase system in Escherichia coli. Res Microbiol 143, 251-261.

Received 4 September 1995; revised 3 November 1995; accepted 8 November 1995. 